\title{
Verzeichnis der Abbildungen in Band II
}

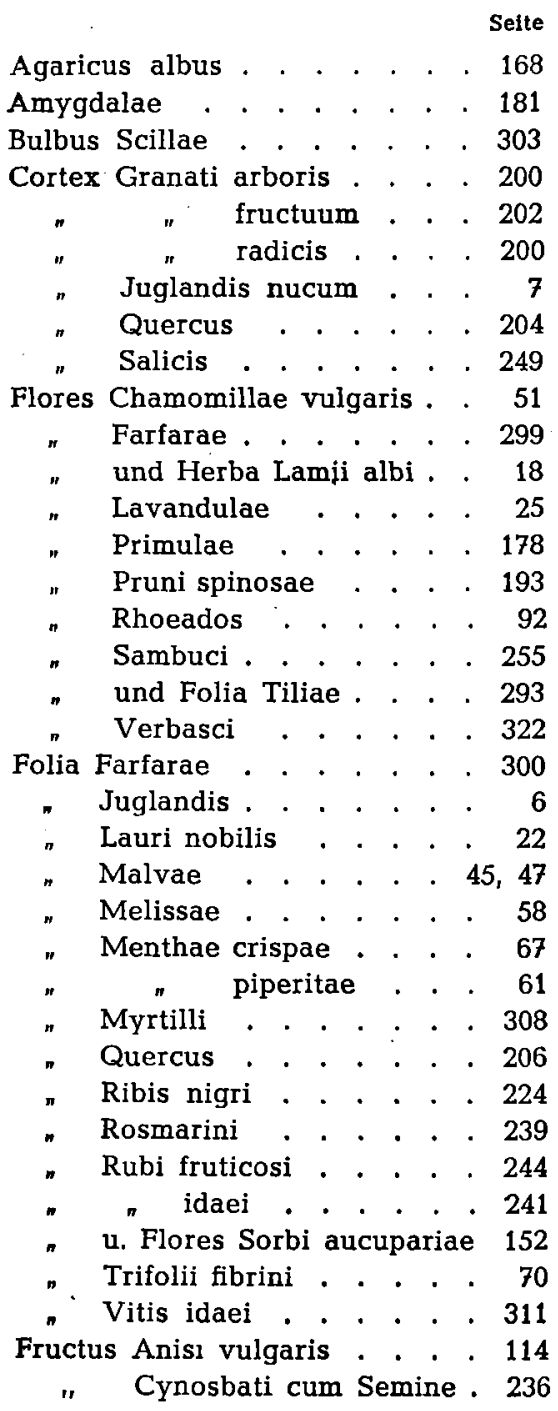




\begin{tabular}{|c|c|c|c|c|c|c|c|c|c|c|c|c|c|}
\hline & & & & & & Selte & & & & & & & Seite \\
\hline lerba & Urticae & & . & 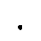 & & . 306 & Rhizom & a Iridis floren & & & & & \\
\hline 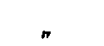 & Verbenae & . & . & . & - & . 324 & $n$ & " pro i & infe & ar & ibus & & \\
\hline 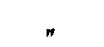 & Veronicae & & . & . & . & . 326 & & Polypodii & & & & - & 16 \\
\hline$"$ & Violae odo & ratae & e. & . & . & . 329 & $"$ & Rhei sinens & & c & $\mathrm{mm}$ & non & \\
\hline$"$ & tric & olori & & - & & . 33 & & round & & & & & \\
\hline " & Virgaureae & . & & - & . & . 277 & $n$ & Rhei & & Sh & si & & \\
\hline ignum & n Juniperi & 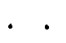 & . & . & 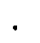 & 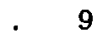 & & sinens & & & & & \\
\hline ycopo & odium . & . & . & . & - & 43 & & rund & & . & & & 21 \\
\hline Mastix & . . . & . & . & . & . & . 154 & $n$ & Tormentilla & & . & ${ }^{\circ}$ & . & 17 \\
\hline $\operatorname{adix~I~}$ & Levistici . & . & . & . & . & 32 & 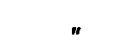 & Veratri albi & & & . & . & . 31 \\
\hline 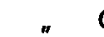 & Ononidis & & & . & . & 7 & ecale & cornutu & lich & & . & & 26 \\
\hline & Petroselini & 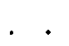 & 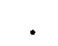 & . & . & . 105 & $n$ & spa & inis & sch & & & 26 \\
\hline & Pimpinellae & & . & . & . & . 117 & Semen & Cynosbati & & • & 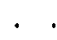 & & . 23 \\
\hline 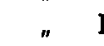 & Primulae . & . . & . & . & . & . 176 & & Erucae & $\cdot$ & - & . & & 27 \\
\hline & Rhei rhapon & tici $f$ & fran & $\mathrm{nz}$. & & & & Foenugraeci & . & . & • & & \\
\hline & mund. & & & - & . & . 219 & & Lini & & & & & \\
\hline & Rhei rhapon & tici $f$ & fran & & & & & Nigellae . & & & & & 72,7 \\
\hline & né & & & . & & 219 & & Paeoniae & & & & & \\
\hline . & Rhei & tici ö & öste & & & . 220 & & Ricini . & & . & . & . & \\
\hline & Rhe & & $\cdot$ & - & 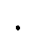 & . 221 & & Psylli . . . & 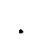 & . & . & . & . 15 \\
\hline & Sapc & rubra & rae & . & . & . 262 & Stipes & Cerasi acidi & & . & & & \\
\hline & Tara & . $\cdot$ & . & . & & . 280 & & Dulcamarae & 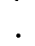 & . & & . & 27 \\
\hline & Valer & 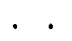 & $\cdot$ & . & - & . 314 & & Laminariae . & 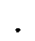 & . & • & . & \\
\hline Iizom & na $\mathrm{Bi}$ & . & . & - & . & . 165 & Tubera & Salep . & . & . & - & - & \\
\hline 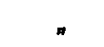 & $\mathrm{He}$ & 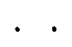 & - & - & . & . & rurion & es Pini . . & - & - & & & \\
\hline & Imperato & & & - & & . 108 & Viscum & a album & & . & & & \\
\hline
\end{tabular}

